\title{
Condições Econômicas e Nível de Qualidade Ambiental no Estado do Rio Grande do Sul
}

\author{
Marivane Vestena Rossato ${ }^{1}$ \\ João Eustáquio de Lima² \\ Viviani Silva Lírio ${ }^{3}$
}

\begin{abstract}
Resumo: A análise da qualidade ambiental e das associações mantidas com o sistema econômico sempre foi tema de grande interesse na comunidade científica e nas organizações públicas e privadas. O estado do Rio Grande do Sul tem apresentado alto Índice de Desenvolvimento Humano (IDH), porém, baixos valores de importantes indicadores de qualidade ambiental. Assim, este estudo teve como objetivo fornecer evidências empíricas acerca de como o nível de atividade econômica interfere na qualidade ambiental dos municípios gaúchos, bem como construir um Índice de Qualidade Ambiental (IQA) e um Índice de Desenvolvimento Humano-Ambiental (IDH-A) para esse estado, como uma alternativa para representar o seu nível de desenvolvimento humano com uma dimensão ambiental. Os resultados indicaram que níveis de atividade econômica mais intensa desencadeiam menor qualidade ambiental. O IQA médio do estado foi estimado em 0,55 e o IDH-A, em 0,25, valor bem abaixo do IDH médio gaúcho, que foi de 0,78. Evidenciou-se ainda, por meio da Análise Exploratória de Dados Espaciais (Aede), a existência de padrões espaciais distintos em relação à renda per capita, ao IQA, ao IDH e ao IDH-A do Rio Grande do Sul, indicando a sua grande heterogeneidade espacial.
\end{abstract}

Palavras-chave: padrão de vida, qualidade ambiental, padrões espaciais.

Abstract: The analysis of the environmental quality and of the associations kept with the economical system has always been of great concern amongst the scientific community and the public and private organizations. The state of Rio Grande do Sul has been presenting a high Index of Human Development (IDH in Portuguese), although, low

\footnotetext{
$1 \quad$ E-mail: marivane@smail.ufsm.br

2 E-mail: jelima@ufv.br

3.E-mail:vslirio@ufv.br
} 
values of important environmental quality indicators. Thus, the present study had the purpose of providing empirical evidences on how the level of economical activity affect the environmental quality of the municipal districts of Rio Grande do Sul as well as to build a Index of Environmental Quality (IQA) and a index of Human-Environmental Development (IDH-A) for this state as an alternative to represent its level of human development with a environmental dimension. Results revealed that more intense levels of economical activity unleash minor environmental quality. The state medium IQA has been estimated in 0,55 and the IDH-A in 0,25, being quite below the medium IDH of Rio Grande do Sul, which was 0,78. It was still evidenced by the Exploratory Analysis of Space Data (Aede) the existence of distinct space patterns in relation to the per capita income, to the IQA, to the IDH and IDH-A of Rio Grande do Sul, indicating its great space heterogeneity.

Key-words: life pattern, environmental quality, space patterns.

Classificação JEL: Q56.

\section{Introdução}

O estado do Rio Grande do Sul experimenta uma concentração da população e das atividades econômicas sobre o mesmo espaço, o que tem causado alterações negativas na qualidade ambiental de seus municípios. Como coloca Bertê (2004), o Rio Grande do Sul encontra-se entre os cinco estados brasileiros com as menores taxas de volume de esgoto tratado e entre os sete com as menores taxas de volume de água tratada distribuída. Temas ligados às poluições atmosférica, hídrica e do solo, e à exaustão dos recursos naturais fazem parte da problemática ambiental do estado. Ao mesmo tempo, conforme registram Magnoli e Araújo (2001), o Relatório sobre o Desenvolvimento Humano no Brasil, elaborado pelo Instituto de Pesquisas Econômicas Aplicadas (Ipea) com base no Índice de Desenvolvimento Humano (IDH), da Organização das Nações Unidas (ONU), aponta o Rio Grande do Sul como um dos estados brasileiros com a melhor qualidade de vida, medida pelo IDH.

O IDH é elaborado pela ONU e é um importante indicador das condições de vida das populações nos diversos países do mundo. Ele combina três componentes do desenvolvimento humano: a longevidade, a educação e a renda.

O IDH varia entre 0 (pior) e 1 (melhor) e combina índices de saúde, educação e renda per capita em um indicador-síntese. Os municípios com IDH até 0,49 têm desenvolvimento humano considerado baixo; os municípios com índices entre 0,5 e 0,79 são tidos como de médio desenvolvimento humano; e municípios com IDH maior que 0,8 têm desenvolvimento humano considerado alto (MAGNOLI e ARAÚJO, 2001). 
Nesse contexto, este estudo tem por objetivo principal identificar as associações entre condições econômicas e qualidade ambiental nos municípios do Rio Grande do Sul, no ano de 2000. Buscou-se, também, construir um Índice de Qualidade Ambiental (IQA) para evidenciar a qualidade ambiental a partir de variáveis de natureza ambiental, bem como um Índice de Desenvolvimento Humano-Ambiental (IDH-A) para representar o nível de desenvolvimento humano, englobando, além das dimensões econômica e social - consideradas pela ONU para elaborar o IDH -, a dimensão ambiental. Ao final, procurou-se identificar padrões espaciais das condições econômicas e ambientais no estado.

Evidencia-se que o IDH deveria refletir adequadamente as condições de vida da população, uma vez que as questões ambientais não são consideradas para sua elaboração. Assim, este estudo inova ao construir e propor um novo índice para representar as condições de vida da população, com a inclusão da dimensão ambiental, o IDH-A.

O referencial teórico que norteou a pesquisa é composto pelos modelos ${ }^{4}$ da economia circular e da economia sustentável, bem como pela teoria das externalidades, que constituem as bases para o entendimento das associações entre condições econômicas e ambientais.

O modelo da economia circular, segundo Pearce e Turner (1989), explicita a relação entre a atividade econômica e o ambiente natural através de três funções econômicas desempenhadas pelo meio ambiente, quais sejam: fornecedor de recursos naturais ao sistema produtivo, assimilador de resíduos e fornecedor de utilidade diretamente na forma de bem-estar. Já o modelo da economia sustentável, conforme registram Pearce e Turner (1989), revela as regras para manejo de recursos e ambiente, bem como para se sustentar a economia: usar recursos renováveis, de tal modo que a taxa de exploração não seja maior que a taxa de regeneração natural; e manter os fluxos de dejetos para o meio ambiente no mesmo nível ou abaixo da capacidade assimilativa do mesmo. A teoria das externatilidades, por sua vez, dispõe sobre os resultados de ações de agentes econômicos, os quais refletem positiva ou negativamente no bem-estar social. Esses reflexos, quando positivos, tendem a proporcionar melhorias à sociedade. Contrariamente, as externalidades negativas ou deseconomias externas trazem ônus à sociedade, sem que esta seja compensada pelo mal que suporta (PINDYCK e RUBINFELD, 1994).

\section{Procedimentos metodológicos}

Inicialmente, relacionaram-se, por meio de análise de regressão, variáveis indicadoras de qualidade ambiental com variáveis que medem o nível e concentração da atividade econômica, com o objetivo de verificar se municípios com maior crescimento econômico apresentam piores níveis de qualidade

4 Para uma boa descrição desses modelos, ver Rossato (2006). 
ambiental. Em seguida, utilizou-se da análise fatorial para construir um Índice de Qualidade Ambiental (IQA) e um Índice de Desenvolvimento HumanoAmbiental (IDH-A) para os municípios gaúchos, sendo o IDH-A concebido como uma versão do IDH que leva em conta as condições ambientais. Por fim, foi utilizada a Análise Exploratória de Dados Espaciais (Aede) para identificar padrões espaciais das condições econômicas e ambientais no estado.

\subsection{Relação entre a qualidade ambiental e o nível de atividade econômica}

No propósito de analisar a relação entre a qualidade ambiental e as condições econômicas dos municípios, foi empregado um modelo de regressão linear multivariada dado por:

$$
Y_{m}=X_{m} \beta_{m}+\varepsilon_{m}, \quad m=1,2,3
$$

em que $Y_{1}$ é o índice de saneamento, $Y_{2}$ é o índice de potencial poluidor da indústria e $Y_{3}$ é o porcentual de áreas com florestas nativas e plantadas e $X$ $=[T U, R P C, P I B I, P I B A]$ é o vetor de variáveis explicativas, sendo TU a taxa de urbanização (\%), $R P C$, a renda per capita (R\$/habitante), PIBI é o produto interno bruto industrial (R\$) e PIBA é o produto interno bruto da agropecuária $(\mathrm{R}$ ); $\varepsilon$ é o vetor de erros aleatórios com matriz de variâncias e covariâncias $E\left(\varepsilon \varepsilon^{\prime}\right)=\Omega=\Sigma \otimes I$, sendo $\Sigma$ a matriz de covariâncias entre os erros das diferentes equações. Assim, dada a possível existência de correlação entre os erros das diferentes equações, a equação 1 foi estimada por Mínimos Quadrados Generalizados (MQG), modelo que fornece estimativas mais eficientes.

As variáveis indice de saneamento e índice de potencial poluidor da indústria, utilizadas para representar a qualidade ambiental, foram obtidas junto à Fundação de Economia e Estatística do Estado do Rio Grande do Sul -FEE (2000). A variável porcentual de áreas com florestas nativas e plantadas, por sua vez, baseou-se no Censo Agropecuário de 1996, realizado pela Fundação Instituto Brasileiro de Geografia e Estatística (FIBGE), última base oficial de dados agropecuários existente quando da realização do estudo. A FIBGE também serviu de fonte para as variáveis utilizadas na caracterização do nível de atividade econômica dos municípios gaúchos.

A análise da relação entre qualidade ambiental e nível de atividade econômica considerou 452 cidades do Rio Grande do Sul. Embora na estrutura estabelecida pela FIBGE, sejam 467 os municípios componentes do estado no ano de 2000, a análise foi realizada tomando-se por base 452 municípios, tendo em vista que para os 15 restantes não existiam dados censitários, para um ou para outro município, específicos para as variáveis consideradas no estudo. 


\subsection{Construção do Índice de Qualidade Ambiental (IQA) e do Índice de Desenvolvimento Humano-Ambiental (IDH-A)}

Um bom indicador, segundo Gallopin (1997 apud Martinez, 2004), é uma variável que agrega, ou mesmo simplifica, as informações relevantes, torna visíveis fenômenos perceptíveis de interesse e quantifica, avalia e comunica dados importantes.

Com base nessa concepção, buscou-se construir um índice que refletisse o nível de qualidade ambiental dos municípios gaúchos, denominado Índice de Qualidade Ambiental (IQA). Correspondente a um número-índice, o IQA foi desenvolvido com o objetivo principal de descrever as condições ambientais dos 452 municípios do estado do Rio Grande do Sul, existentes no ano de 2000. Para sua elaboração, tomou-se como base a metodologia proposta por Soares et al. (1999), que desenvolveram um Índice de Desenvolvimento Municipal (IDM) para os municípios do Ceará.

As variáveis utilizadas para a construção do IQA foram: porcentual de áreas com florestas nativas e plantadas; índice de saneamento; índice de potencial poluidor da indústria; porcentual de domicílios particulares permanentes que jogam lixo em terreno baldio ou logradouro; e porcentual de domicílios particulares permanentes que queimam lixo em sua propriedade. Evidencia-se que as variáveis porcentual de domicílios particulares permanentes que jogam lixo em terreno baldio e daqueles que queimam lixo em sua propriedade foram extraídas da FIBGE.

A elaboração do IQA se deu por meio da equação 2:

$$
I Q A_{i}=\sum_{j=1}^{k} \frac{\lambda_{j}}{\operatorname{tr}(R)} F_{j i}
$$

em que:

$I Q A_{i}=$ Índice de Qualidade Ambiental do município $i ;$

$\lambda_{j}=j$-ésima raiz característica da matriz de correlação $\mathrm{R}$ das variáveis ambientais;

$k=$ número de fatores escolhidos;

$F_{j i}=$ escore fatorial do fator $j$ no município $i$; e

$t r=$ traço da matriz de correlação $R_{\text {pxp }}$.

A partir do Índice de Qualidade Ambiental (IQA), buscou-se criar um índice que refletisse o nível de desenvolvimento humano nos municípios gaúchos, denominado Índice de Desenvolvimento Humano-Ambiental (IDH-A). Isso porque os índices existentes e mais amplamente divulgados não abarcam a dimensão da realidade ambiental para a análise do nível de desenvolvimento humano da população.

Para a estimação e elaboração do IDH-A, foram utilizados os procedimentos metodológicos desenvolvidos e propostos por Lemos (2001) para a construção de índices de degradação ambiental, adaptando-se ao caso específico. 
Antes, porém, foi necessário criar um índice parcial, o Índice Parcial de Desenvolvimento Humano-Ambiental (IPDH-A), estimado por meio da equação 3 , sendo que os fatores comuns (F) foram obtidos através da técnica de análise fatorial, sobre as variáveis já definidas.

$$
I P D H-A_{i}=\left(\sum_{j=1}^{k} F_{i j}^{2}\right)^{1 / 2}
$$

em que IPDH- $\mathrm{A}_{i}$ é o Índice Parcial de Desenvolvimento Humano-Ambiental associado ao i-ésimo município; e $F_{i j}$ ã̃o os escores fatoriais estimados segundo o procedimento de decomposição em componentes principais. Vale destacar que o IPDH-A visou apenas à elaboração do IDH-A, não apresentando relação com os demais índices criados e analisados neste estudo.

Conduziu-se uma análise fatorial, com base nas observações feitas para os indicadores: renda per capita, esperança de vida ao nascer e taxa bruta de frequência - obtidos junto à FIBGE -, além do Índice de Qualidade Ambiental (IQA).

De acordo com Lemos (2001), como se espera que os escores associados aos municípios tenham distribuição simétrica em torno da média zero, metade deles terá sinais negativos e a outra metade, sinais positivos. Para evitar que altos escores fatoriais negativos elevem a magnitude dos índices associados a esses municípios, torna-se necessária a transformação mostrada na equação (4), tendo por objetivo inseri-los todos no primeiro quadrante:

$$
F_{i j}^{*}=\frac{\left(F_{i j}-F_{\min }\right)}{\left(F_{\max }-F_{\min }\right)}
$$

em que $F_{\text {min }}$ e $F_{\text {max }}$ são os valores mínimo e máximo observados para os escores fatoriais associados aos municípios do Rio Grande do Sul e $F_{i j}^{*}$ são os escores fatoriais definidos no intervalo fechado entre 0 e 1.

O cálculo geométrico do Índice Parcial de Desenvolvimento HumanoAmbiental (IPDH-A) é apresentado na Figura 1.

Figura 1. Construção geométrica do IPDH-A.

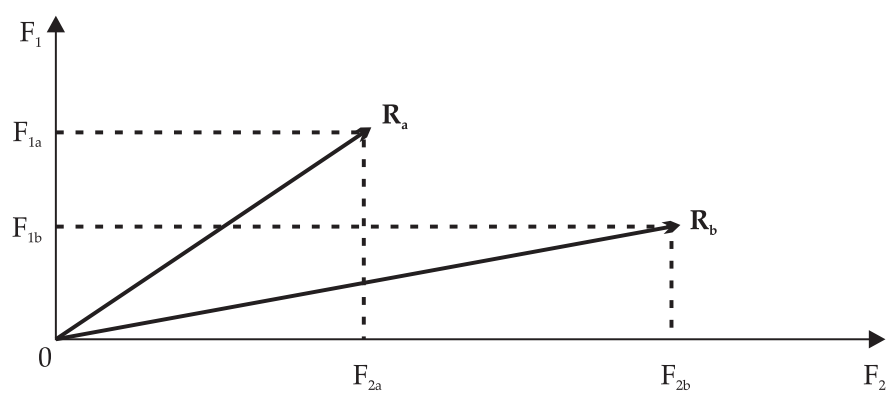

Fonte: Lemos (2001). 
A Figura 1 mostra que, associados ao município A, estão os escores fatoriais $F_{1 a}$ e $F_{2 a}$, em que o vetor $R_{a}$ é a resultante associada a esses escores, assim definidos:

$$
R_{a}=\left(F_{1 a}^{2}+F_{2 a}^{2}\right)^{1 / 2}
$$

A magnitude do IPDH-A associada aos municípios A e B é obtida exatamente pelo tamanho da resultante $R_{a}$ ou $R_{b}$ r respectivamente. O próximo passo consistiu na análise de regressão para estimar os pesos atribuídos a cada uma das variáveis que entraram na composição do IPDH-A. Para isso, utilizou-se a seguinte equação:

$$
I D H-A_{i}=\left(\sum_{j=1}^{p} P_{j} X_{i}\right), \text { com } \sum_{j=1}^{p} P_{j}=1
$$

em que os pesos $P_{j}$ são estimados por regressão múltipla, em que a variável dependente é o IPDH- $\mathrm{A}_{i}$ e as variáveis explicativas são os indicadores de qualidade de vida, a saber: renda per capita, taxa de frequência escolar, esperança de vida ao nascer e Índice de Qualidade Ambiental (IQA).

\subsection{Análise exploratória de dados espaciais (Aede)}

A Análise Exploratória de Dados Espaciais (Aede) é geralmente utilizada para testar a existência de padrões espaciais, como a heterogeneidade espacial e a dependência espacial. Para a verificação do comportamento de atributos de cada localidade de uma região contínua no espaço, pode-se utilizar o Índice de Correlação Espacial de Moran (Moran, 1948). Formalmente, o indicador I de Moran é apresentado da seguinte forma:

$$
I=\frac{n}{\sum_{i} \sum_{j} w_{i j}}\left(\frac{\sum_{i} \sum_{j} w_{i j}\left(y_{i}-\bar{y}\right)\left(y_{j}-\bar{y}\right)}{\sum_{i}\left(y_{i}-\bar{y}\right)^{2}}\right)
$$

em que $y_{i}$ é a variável de interesse, $n$ é o número de unidades espaciais e $w_{i j}$ é o peso espacial para o par de unidades $i$ e $j$, medindo-se o grau de interação entre elas.

O valor do I de Moran varia de -1 a 1 . Valores próximos de zero indicam a inexistência de autocorrelação espacial entre os valores da região e seus vizinhos. Esse cálculo utiliza-se de uma matriz de pesos $W$, expressando a conexão entre as localidades de uma região. A matriz de pesos espaciais $W$ tem como objetivo capturar os efeitos de contiguidade e vizinhança sobre os dados analisados. Segundo Almeida (2004), essa matriz pode ser elaborada com base em critérios como a distância entre localidades.

O Índice de Moran pode ser apresentado em um Mapa (Moran scaterplot), fornecendo informações em termos espaciais. Quando positivos, salienta Anselin (1994), os indicadores locais sugerem a formação de significativas aglomerações 
de valores similares. No entanto, quando negativos, indicam a formação de significativas regiões heterogêneas. O Moran scaterplot fornece quatro alternativas de associação espacial: Alto-Alto, Alto-Baixo, Baixo-Baixo e Baixo-Alto.

Segundo Almeida (2004), as unidades espaciais pertencentes ao agrupamento Alto-Alto exibem valores altos da variável de interesse, sendo rodeadas por unidades espaciais que também apresentam valores altos. Já um agrupamento Alto-Baixo diz respeito a um cluster no qual uma unidade espacial qualquer com um alto valor da variável de interesse é circunvizinha de unidades espaciais com baixo valor. Um agrupamento Baixo-Baixo, por sua vez, é aquele com valores baixos circundados por unidades espaciais que ostentam valores igualmente baixos. E, por último, tem-se o agrupamento Baixo-Alto, que se refere a um cluster no qual uma unidade espacial qualquer com um baixo valor da variável de interesse é circunvizinha de unidades espaciais com alto valor.

A análise de agrupamento, também denominada análise de cluster, utilizada para a Análise Exploratória de Dados Espaciais, é definida por Barroso e Artes (2003) como um conjunto de técnicas empregadas na identificação de padrões de comportamento em bancos de dados, através da formação de grupos homogêneos de casos. Essa técnica tem o intuito de proporcionar uma ou várias partições na massa de dados em grupos, por algum critério de classificação (características, variáveis), o que possibilita a simplificação da interpretação dos resultados. Nesse sentido, conforme menciona Valentim (2000), nos clusters formados, os elementos de mesmo grupo devem ser, o mais próximo possível, semelhantes, enquanto os elementos de grupos diferentes devem ser, o mais próximo possível, desiguais.

\section{Resultados e discussão}

\subsection{Condições econômicas e qualidade ambiental no Rio Grande do Sul}

As estimativas apresentadas na Tabela 1 apontam a relação entre qualidade ambiental e condições econômicas nos municípios do Rio Grande do Sul, em 2000. Observa-se que os indicadores taxa de urbanização e PIB Agropecuário são estatisticamente significativos, em nível de significância de 1\% de probabilidade, enquanto a renda per capita mostrou-se estatisticamente significativa a 5\% de probabilidade, na determinação do índice de saneamento nos municípios gaúchos. Ou seja, demonstraram-se importantes para explicar a qualidade ambiental, considerando-se o aspecto ambiental saneamento básico. Conduzem à análise de que, quanto mais intensos são os níveis de atividade econômica, melhores são os índices de saneamento. Os municípios com maiores taxas de urbanização, renda per capita e PIB Agropecuário detêm os maiores índices de saneamento. Essa situação se revela porque foram considerados na pesquisa os 
meios urbano e rural, em conjunto, e fica evidente que os índices de saneamento são maiores naqueles municípios mais urbanizados, visto que os serviços de água encanada e coleta de esgoto são ofertados à população urbana.

Tabela 1. Estimativas da associação entre qualidade ambiental e condições econômicas nos municípios do Rio Grande do Sul, 2000.

\begin{tabular}{lcccccc}
\hline \multirow{2}{*}{$\begin{array}{c}\text { Variáveis } \\
\text { Explicativas }\end{array}$} & \multicolumn{2}{c}{ Índice de Saneamento } & \multicolumn{2}{c}{$\begin{array}{c}\text { Índice de Potencial } \\
\text { Poluidor da Indústria }\end{array}$} & $\begin{array}{c}\text { Porcentual de Áreas com } \\
\text { Florestas Nativas e Plantadas }\end{array}$ \\
\cline { 2 - 7 } & Coeficiente & $\begin{array}{c}\text { Desvio } \\
\text { Padrão }\end{array}$ & Coeficiente & $\begin{array}{c}\text { Desvio } \\
\text { Padrão }\end{array}$ & Coeficiente & $\begin{array}{c}\text { Desvio } \\
\text { Padrão }\end{array}$ \\
\hline Constante & $0.095988^{* * *}$ & 0.020389 & $0.156773^{* * *}$ & 0.039730 & $12.177670^{* * *}$ & 1.697685 \\
Taxa de Urbanização & $0.004012^{* * *}$ & 0.000274 & $-0.000043^{\text {ns }}$ & 0.000534 & $-0.054117^{* *}$ & 0.022816 \\
Renda Per Capita & $0.000178^{* *}$ & 0.000087 & $-0.000685^{* * *}$ & 0.000171 & $0.032541^{* * *}$ & 0.007290 \\
PIB Industrial & $0.000023^{\text {ns }}$ & 0.000017 & $0.002499^{* * *}$ & 0.000034 & $0.000184^{*}$ & 0.001467 \\
PIB Agropecuário & $0.000376^{* * *}$ & 0.000143 & $-0.000991^{* * *}$ & 0.000278 & $-0.025656^{* *}$ & 0.011886 \\
\hline$R^{2}$ & 0.504 & & 0.939 & & 0.060 & $5.211^{* * *}$ \\
F & $101.706^{* * *}$ & & $1544.940^{* * *}$ & & &
\end{tabular}

*** significativo a $1 \%$.

** significativo a $5 \%$.

* significativo a $10 \%$.

ns - não significativo.

Fonte: Resultados da pesquisa.

O PIB Agropecuário mantém relação direta com o saneamento. Isso porque a maioria dos municípios gaúchos que tem na agropecuária a base de suas economias desenvolve as atividades com o emprego de técnicas avançadas de produção, diminuindo a oferta de mão de obra. A população desses municípios concentra-se no meio urbano, onde há maiores índices de saneamento.

As relações de produção, representadas pelo PIB Industrial e pelo PIB Agropecuário, revelam que, nos municípios com maior PIB Industrial, a potencialidade de meios físicos, água, solo e ar estarem poluídos por fonte industrial também é maior. Situação oposta ocorre nas localidades com maior PIB Agropecuário. No entanto, o nível de renda está associado de forma negativa ao Índice de Potencial Poluidor da Indústria. Fica evidenciado que os municípios com maior padrão de vida não são os mais industrializados e apresentam maior potencialidade de esses meios físicos estarem poluídos por fonte industrial.

As estimativas geradas para a cobertura do solo mostram que os indicadores taxa de urbanização, renda per capita, PIB Industrial e PIB Agropecuário foram importantes, quando se considera o nível de significância dos coeficientes, para explicar as variações ocorridas no porcentual de áreas com florestas nativas e plantadas. Evidencia-se, no entanto, que o modelo não foi bem ajustado, pois o coeficiente de determinação $\left(\mathrm{R}^{2}\right)$ mostrou que apenas $6 \%$ da variação 
no porcentual de áreas florestais é explicada pelos indicadores que medem o nível e a concentração da atividade econômica. Apesar dessa estimativa, o teste $\mathrm{F}$ da significância global da regressão foi significativo a $1 \%$. Ressalta-se que essa situação pode estar atrelada à característica dos dados, que são de seção cruzada.

$\mathrm{O}$ indicador de urbanização se revelou importante na determinação do porcentual de áreas florestais, dada a maior demanda de recursos naturais para o abastecimento da população que reside no meio urbano. Além disso, a urbanização desencadeia um processo natural de desmatamento, ou seja, para urbanizar, mais espaços naturais são demandados.

Com relação ao PIB Agropecuário, as estimativas revelam que, quanto mais intensas as relações de produção agropecuária, menores eram os porcentuais de áreas com florestas nos municípios do Rio Grande do Sul, em 2000.

Quanto à renda per capita, contudo, os porcentuais de áreas com florestas nos municípios gaúchos são maiores nas regióes que detêm níveis de renda mais elevados. É o caso da região do Planalto Médio, onde a geomorfologia não favorece o desenvolvimento da atividade agrícola.

\subsection{Quantificação do nível de qualidade ambiental dos municípios gaúchos}

Após medir o nível de qualidade ambiental, este estudo focou a elaboração do Índice de Desenvolvimento Humano-Ambiental (IDH-A). O intuito foi contribuir para a representação da qualidade de vida humana e evidenciar sua importância, nessa função, de forma mais completa, à medida que se considerou, além da renda per capita, educação e saúde, o componente ambiental.

A técnica de análise fatorial mostrou-se adequada com base no teste de Bartlett $\left(\chi^{2}=446,8\right)$ e no índice de Kaiser-Meyer-Olkin (KMO = 0,65). A avaliação do método dos principais componentes produziu como resultado dois fatores com raízes características maiores que 1 , cuja contribuição acumulada para a explicação da variância total dos indicadores ambientais utilizados é de 65,9\%. A Tabela 2 apresenta quais fatores relacionam-se com quais variáveis, ao exibir as cargas fatoriais e as comunalidades.

Tabela 2. Cargas fatoriais e comunalidades.

\begin{tabular}{lccc}
\hline \multirow{2}{*}{ Variáveis } & \multicolumn{3}{c}{ Cargas Fatoriais } \\
\cline { 2 - 4 } & $F 1$ & $F 2$ & Comunalidades \\
\hline X $_{1}$ - Porcentual de áreas com florestas & 0,065 & 0,954 & 0,915 \\
X $_{2}$ - Índice de saneamento & $-0,804$ & 0,012 & 0,647 \\
X $_{3}$ - Índice de potencial poluidor da indústria & $-0,502$ & 0,272 & 0,326 \\
X $_{4}$ - Lixo lançado em terreno baldio & 0,760 & 0,214 & 0,624 \\
\multicolumn{1}{c}{ X $_{5}$ - Lixo queimado na propriedade } & 0,881 & $-0,089$ & 0,784 \\
\hline
\end{tabular}

Fonte: Resultados da pesquisa. 
Os resultados apontados na Tabela 2 foram obtidos após a rotação ortogonal, utilizando-se o método Varimax. Conforme Everitt (1977), essa rotação possibilita uma melhor interpretação dos dados.

As cargas fatoriais acima de 0,65, destacadas em negrito, buscam evidenciar os indicadores mais fortemente associados a determinado fator. Pode-se constatar que o Fator 1 encontra-se mais fortemente correlacionado com as variáveis índice de saneamento, porcentual de lixo lançado em terreno baldio e porcentual de lixo queimado na propriedade, enquanto o Fator 2 está mais correlacionado com a variável porcentual de áreas com florestas nativas e plantadas. Desse modo, o Fator 1, doravante denominado Infraestrutura Sanitário-Ambiental, sintetiza as variáveis que captam o nível de atendimento à população com serviços de saneamento e destino dado ao lixo. Já o Fator 2, denominado Cobertura Vegetal, representa a variável que capta a intensidade da cobertura vegetal do Rio Grande do Sul. Os valores encontrados revelam que, se houver aumento na cobertura vegetal através de florestas, maiores serão os valores dos índices analisados e menor o impacto negativo na qualidade ambiental do estado. Evidencia-se que a variável índice de potencial poluidor da indústria apresentou coeficientes numéricos baixos para os dois fatores comuns, considerando o valor estabelecido por Souza e Lima (2003).

Transcorrida a obtenção dos fatores e coeficientes (cargas fatoriais) necessários para a estimação dos escores fatoriais, calculou-se o Índice de Qualidade Ambiental (IQA). Os resultados apontam que o estado do Rio Grande do Sul possui um IQA médio de 0,55, indicando que a qualidade ambiental está 45 pontos porcentuais abaixo do máximo (100\%). Em adição a esse fato, apenas $17 \%$ dos municípios gaúchos obtiveram valores do IQA acima de 0,7 e 22 municípios apresentaram IQA abaixo de 0,3. As piores posições são ocupadas por Canoas, Porto Alegre, Caxias do Sul, Rio Grande, Esteio e Gravataí, pertencentes às regiões do Planalto Médio e metropolitana de Porto Alegre, que exercem importante função no comando econômico do estado.

Pode-se inferir que o sistema econômico dos municípios gaúchos com baixa qualidade ambiental, para os indicadores ambientais considerados, não está funcionando como um sistema sustentável, ou seja, as funções econômicas do meio ambiente, estabelecidas por Pearce e Turner (1989), estão comprometidas. Ainda, a retirada da cobertura vegetal representa a transformação pela qual o espaço natural gaúcho passou e é oriunda de ações desenvolvidas por agentes econômicos que são traduzidas em externalidades.

A distribuição dos dados do IQA se concentra no intervalo de 0,5 a 0,6 , conforme pode ser verificado no histograma de frequência, expresso na Figura 2. 
Figura 2. Histograma de frequência dos valores do Índice de Qualidade Ambiental (IQA) nos municípios do Rio Grande do Sul, 2000.

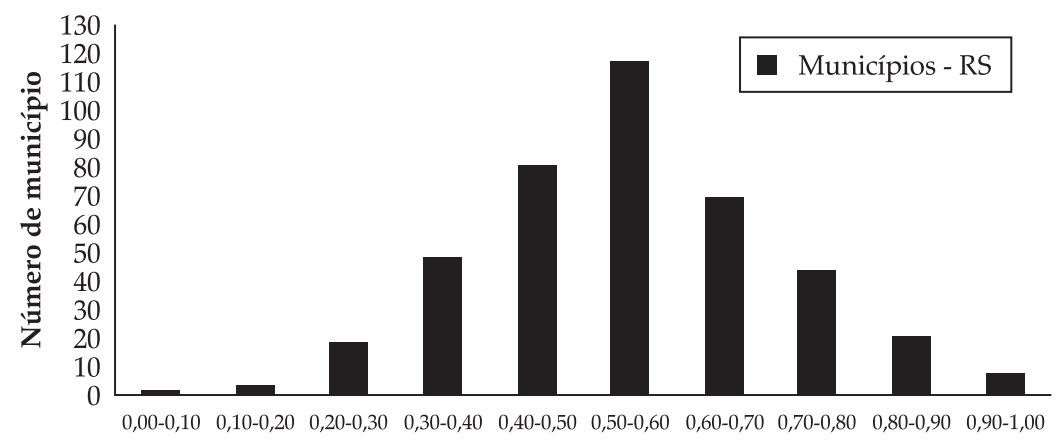

Intervalos de freqüência

Fonte: Resultados da pesquisa.

\section{3. Índice de Desenvolvimento Humano-Ambiental (IDH-A) e Índice de Desenvolvimento Humano (IDH) dos municípios do Rio Grande do Sul}

O Índice de Desenvolvimento Humano-Ambiental (IDH-A) médio estimado para o Rio Grande do Sul, em 2000, foi de 0,25, valor cerca de três vezes menor que o registrado pelo $\mathrm{IDH}^{5}$ da $\mathrm{ONU}(0,78)$, que não considera as condições do meio ambiente.

A Figura 3 apresenta a distribuição do IDH e do IDH-A nos municípios gaúchos, em 2000. Observa-se maior concentração do IDH em torno dos valores 0,7 e 0,8. Bem abaixo do índice da ONU, os dados do IDH-A concentram-se nos intervalos de frequência de 0,1 a 0,2 e entre 0,2 e 0,3 . Assim, quando a qualidade ambiental dos municípios gaúchos é considerada para a determinação do nível de desenvolvimento humano, este é reduzido significativamente, visto que o IQA médio é de 0,55.

5 O IDH da ONU é calculado como uma média aritmética simples de três índices: Índice de Longevidade, Índice de Educação e Índice de Renda Per Capita. O valor de IDH $=0,78$ é inferior ao divulgado para o RS pela ONU $(0,81)$, devido ao fato de terem sido desconsiderados os municípios que não apresentavam dados para um ou para outro indicador, incluídos nesta pesquisa. 
Figura 3. Histograma de frequência dos valores do Índice de Desenvolvimento Humano (IDH) e do Índice de Desenvolvimento Humano-Ambiental (IDH-A). Rio Grande do Sul, 2000.

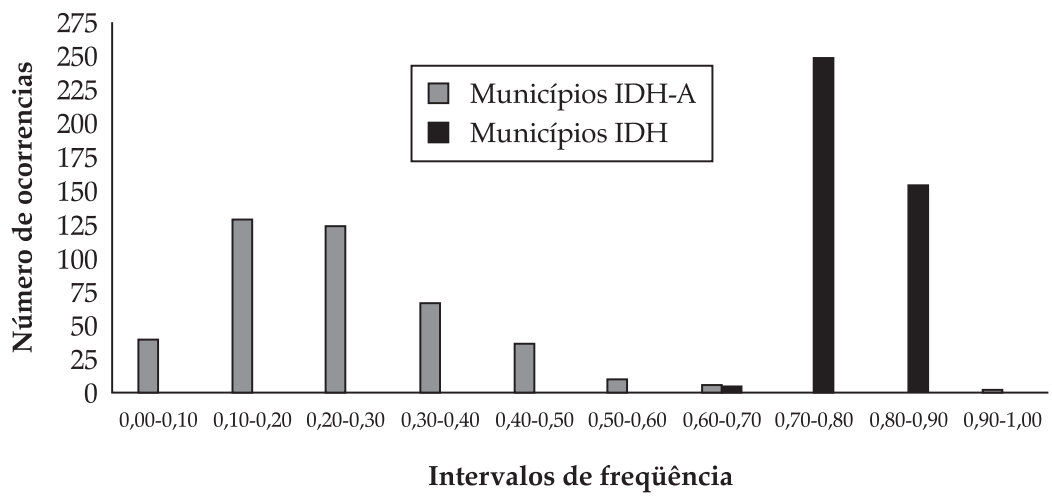

Fonte: Resultados da pesquisa.

\subsection{Padrões espaciais da renda e da qualidade ambiental no Rio Grande do Sul}

Com o objetivo de identificar a distribuição espacial da qualidade ambiental e das condições econômicas (renda per capita), foram elaborados mapas com os diversos indicadores. A Figura 4 apresenta a distribuição espacial do Índice de Qualidade Ambiental (IQA), elaborado para os municípios do Rio Grande do Sul.

Figura 4. Clusters espaciais do Índice de Qualidade Ambiental (IQA) no Rio Grande do Sul, 2000.

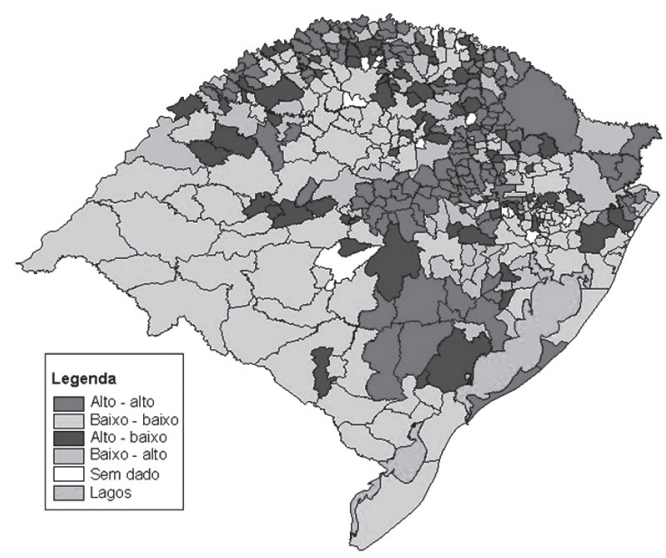

Fonte: Resultados da pesquisa. 
Nota-se que há um cluster com alta qualidade ambiental, acima da média e com vizinhança também acima da média (Alto-Alto), concentrado na região central e em direção ao nordeste do Rio Grande do Sul. Fazem parte desse grupo municípios como Candelária, Vacaria, Esmeralda e Muitos Capões. Além desse, existe outro agrupamento, que inclui Encruzilhada do Sul e municípios dos arredores, ao sul do estado. Os outros clusters são menores e mais esparsos.

Os clusters de municípios com baixa qualidade ambiental (Baixo-Baixo) correspondem à grande parte do território gaúcho. O cluster maior iniciase no extremo sul do estado, em Santa Vitória do Palmar, ligando a região da Campanha Gaúcha ao norte do estado, com os municípios de Palmeira das Missões, Boa Vista das Missões e Coronel Bicaco.

A Figura 5 apresenta os grupos estatisticamente significativos em relação à renda per capita. Observa-se um cluster de riqueza concentrado no corredor da economia do estado do Rio Grande do Sul, ou seja, o eixo que liga a região metropolitana de Porto Alegre até o município de Caxias do Sul, na região do Planalto Médio. Os outros agrupamentos são menores e mais esparsos.

Figura 5. Clusters espaciais da renda per capita no Rio Grande do Sul, 2000.

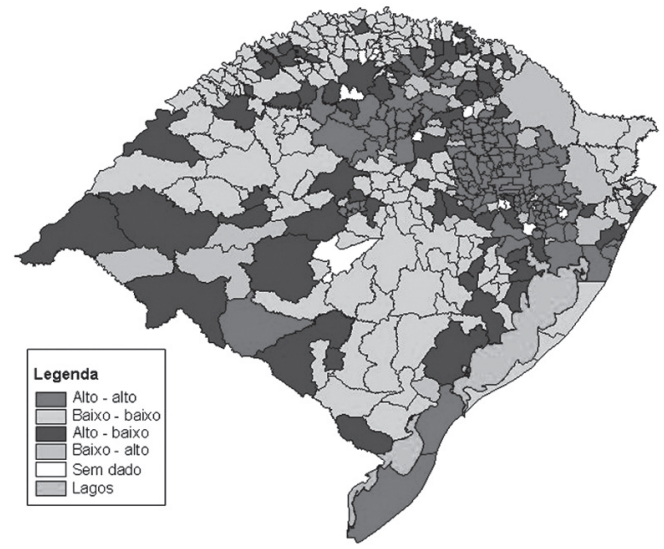

Fonte: Resultados da pesquisa.

O cluster Baixo-Baixo faz o corredor centro-sul do estado, ligando Salto do Jacuí e Tunas, na região central, aos municípios de Herval e Arroio Grande, no extremo sul do estado. Há um grupo com baixas condições econômicas, que começa no Planalto Oeste e se estende ao Planalto Norte. Municípios como Tupanciretã, Santiago, Itaqui e Alpestre fazem parte desse cluster.

A comparação do padrão de distribuição espacial das estimativas do Índice de Qualidade Ambiental (IQA) com o da renda per capita revela que os clusters de municípios com as melhores condições econômicas são os clusters que 
apresentam baixa qualidade ambiental, enquanto aqueles com baixa condição econômica exibem alta qualidade ambiental. Assim, de acordo com a teoria da economia sustentável, verifica-se no estado do Rio Grande do Sul o paradigma da substituição, em que o padrão de vida, representado pela renda per capita, é assegurado através da concessão de recursos naturais. A deterioração da qualidade ambiental representa o comprometimento das funções econômicas do meio ambiente. Evidencia-se, dessa maneira, que a forma de desenvolvimento praticada pelos agentes econômicos está gerando efeitos externos negativos (externalidades) ao meio ambiente, como enfatizado por Pearce e Turner (1989).

\subsection{Padrões espaciais do Índice de Desenvolvimento Humano (IDH) e do Índice de Desenvolvimento Humano-Ambiental (IDH-A) no Rio Grande do Sul}

O Índice de Desenvolvimento Humano(IDH) e o Índice de Desenvolvimento Humano-Ambiental (IDH-A) foram avaliados, também, em um contexto geográfico (Figura 6), em que se verificou a dependência espacial dos índices.

Figura 6. Clusters espaciais do Índice de Desenvolvimento Humano (IDH) no Rio Grande do Sul, 2000.

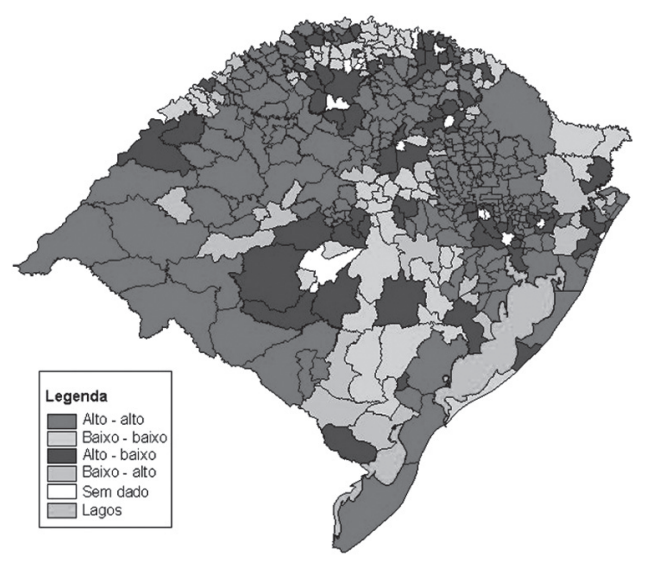

Fonte: Resultados da pesquisa.

O padrão de distribuição espacial do IDH apresenta os altos valores nas duas concentrações maiores de municípios, sendo uma na região da Campanha Gaúcha, que se estende até o noroeste, perfazendo um core ao oeste do estado, e a outra no Planalto Médio (Figura 6). Além dessas, outras concentrações com alto desenvolvimento humano aparecem no sul e litoral do Rio Grande do Sul. Verifica-se, assim, a predominância de valores acima da média (Alto-Alto) para o 
IDH do estado, no contexto espacial. A distribuição espacial dos valores do IDH associa aos baixos valores localizações dispersas na região central gaúcha, bem como um cluster ao norte, noroeste e leste do estado.

A partir da inclusão do IQA na representação do nível de desenvolvimento humano gaúcho, este foi reduzido consideravelmente, como pode ser verificado na Figura 7. A distribuição espacial dos dados do IDH-A apresenta uma configuração diferente da dos valores do IDH. Associam-se aos altos valores duas pequenas concentrações de municípios, sendo uma na região do Planalto Médio, mais objetivamente na Serra Gaúcha, e a outra no Planalto Noroeste, que inclui municípios como Santiago, Bossoroca, Itacurubi e São Francisco de Assis.

Figura 7. Clusters espaciais do Índice de Desenvolvimento Humano-Ambiental (IDH-A) no Rio Grande do Sul, 2000.

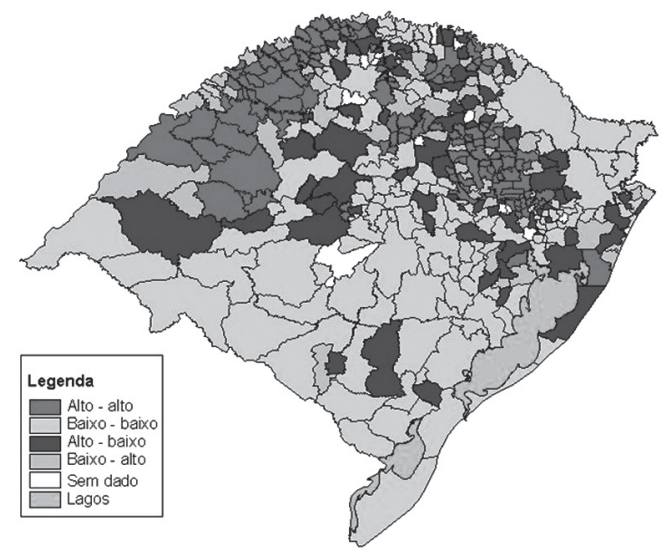

Fonte: Resultados da pesquisa.

Os clusters que tiveram Baixo-Baixo IDH-A (ou seja, índice abaixo da média) correspondem à maior parte do território gaúcho. São municípios caracterizados por condições econômicas desfavoráveis - representadas pela variável renda per capita na composição do índice -, com vizinhos na mesma situação. $\mathrm{O}$ cluster maior inicia-se na região central, se estendendo até o extremo sul, com o município de Santa Vitória do Palmar, passando ainda pelo extremo leste, na região da Campanha, com os municípios de Uruguaiana e Barra do Quaraí.

A superposição dos mapas de clusters espaciais, apresentados nas figuras 6 e 7, permite inferir que a qualidade ambiental se constitui em um redutor do nível de desenvolvimento humano no Rio Grande do Sul. Há uma queda considerável do número de municípios com padrão Alto-Alto, ao passo que aumenta o padrão Baixo-Baixo, indicando que a inclusão da dimensão ambiental reduz significativamente o nível de desenvolvimento humano. 


\section{Conclusões}

Os resultados deste trabalho permitem tirar algumas conclusões sobre as relações entre condições econômicas e qualidade ambiental no Rio Grande do Sul, em 2000. Identificou-se associação positiva entre indicadores econômicos e índice de saneamento, ou seja, municípios mais urbanizados e desenvolvidos são os mais atendidos com serviços de água encanada e rede geral ou pluvial de esgoto. As estimativas para a cobertura do solo com florestas nativas e plantadas permitem inferir que municípios mais urbanizados e com atividades agrícola e pecuária fortes são detentores de menores porcentuais de áreas com florestas nativas e plantadas. Isso implica que a urbanização, junto com o desenvolvimento das atividades agrícola e pecuária no estado, desencadeou um processo de desmatamento, com a ocupação de áreas territoriais.

O nível de qualidade ambiental dos municípios gaúchos, para os indicadores considerados, ficou 45 pontos porcentuais abaixo do máximo (100\%). Já os resultados obtidos para o Índice de Desenvolvimento Humano-Ambiental (IDH-A) evidenciam que a dimensão ambiental dos municípios gaúchos reduz significativamente o nível de desenvolvimento humano.

Ao buscar uma configuração espacial para o Índice de Qualidade Ambiental (IQA) e para a renda per capita, o padrão de distribuição apontou que os clusters de municípios com alto nível de renda, com vizinhos na mesma situação, apresentam baixo IQA. Esse cenário remete às formas de desenvolvimento praticadas no Rio Grande do Sul, que não estão contribuindo para a preservação do meio ambiente, e à importância da inclusão da variável ambiental nos modelos de desenvolvimento.

\section{Referências Bibliográficas}

ALMEIDA, E. S. Curso de econometria espacial aplicada. Piracicaba: ESALQ-USP, 2004. 125p. (Mimeo).

ANSELIN, L. Exploratory spatial data analysis and geographic information systems. In: PAINHO, M. (Ed.) New tools for spatial analysis: proceedings of the workshop. Luxemburgo: EuroStat, 1994. p. 45-54.

BARROSO, L. P; ARTES, R. Análise multivariada. São Paulo: Universidade de São Paulo, 2003. 156 p. (Mimeo.).

BERTÊ, A. M. Problemas ambientais no Rio Grande do Sul: uma tentativa de aproximação. In: VERDUM, R.; BASSO, L. A.; SUERTEGARAY, D. M. A. Rio Grande do Sul: paisagens e territórios em transformação. 1. ed. Porto Alegre: Editora da UFRGS, 2004. p. 71-83.

EVERITT, B. Cluster analysis. London, England: Heinemann Educational Books, 1977. 122p. 
604 - Condições Econômicas e Nível de

Qualidade Ambiental no Estado do Rio Grande do Sul

FUNDAÇÃO ESTATÍSTICA DO ESTADO - FEE. (2000). Idese. Disponível em: www.fee.com.br. Acesso em 24 jan. 2006.

FUNDAÇÃO INSTITUTO BRASILEIRO DE GEOGRAFIA E ESTATÍSTICA FIBGE. (2000). Censo demográfico - 2000. Disponível em: <www.ibge.gov.br>. Acesso em 02 abr. 2005.

. (2000). Pesquisa nacional de saneamento básico - 2000. Disponível em : <www.ibge.gov.br>. Acesso em 03 jul. 2005.

. (1996). Censo agropecuário - 1995/1996. Disponível em: <www.ibge.gov. br>. Acesso em 20 fev. 2006.

LEMOS, J. J. S. Níveis de degradação no Nordeste Brasileiro. Revista Econômica do Nordeste, Fortaleza, CE, v. 32, n. 3, p. 406-429, 2001.

MAGNOLI, D.; ARAÚJO, R. Geografia geral e do Brasil: paisagem e território. São Paulo: Moderna, 2001. 432p.

MARTINEZ, R. Q. Indicadores de sustentabilidade: avanços e desafios para a América Latina. In: ROMEIRO, A. R. (Org.). Avaliação e contabilização de impactos ambientais. São Paulo: Editora da UNICAMP, 2004. p. 252-270.

MORAN, P. The interpretation of statistical maps. Journal of the Royal Statistical Society, 1948.10 b: 243-251.

PEARCE, D. W.; TURNER, R. K. Economics of natural resources and the environment. Baltimore: The John Hopkins University Press, 1989. 378p.

PINDYCK, R. S.; RUBINFELD, D. L. Microeconomia. São Paulo: Makron Books, 1994. $968 \mathrm{p}$.

ROSSATO, M. V. Associações entre qualidade ambiental e nível de desenvolvimento humano no Estado do Rio Grande do Sul. 2006. 138 f. Tese (Programa de PósGraduação em Economia Aplicada - Mestrado e Doutorado) - Universidade Federal de Viçosa, Viçosa, MG. 2006.

SOARES, A.C.L.G.; GOSSON, A.M.P.M.; MADEIRA, M.A.L.H.; TEIXEIRA, V.D.S. Índice de Desenvolvimento Municipal: Hierarquização dos Municípios do Ceará no ano de 1997. Revista Paranaense de Desenvolvimento, Curitiba, PR, v. 28, n.97, p. 71-89. 1999.

SOUZA, P. M.; LIMA, J. E. Intensidade e dinâmica da modernização agrícola no Brasil e nas unidades da federação. Revista Brasileira de Economia, v. 57, n. 4, p. 795-824, out./dez. 2003.

VALENTIN, J. L. Ecologia numérica - uma introdução à análise multivariada de dados ecológicos. Rio de Janeiro: Interciência, 2000. 118 p. 